Original Paper http://ajol.info/index.php/ijbcs $\quad$ http://indexmedicus.afro.who.int

\title{
Hepatoprotective and antioxidant effects of Acanthospermum hispidum (DC) leaves on carbon tetrachloride-induced acute liver damage in rat
}

\author{
Mabozou KPEMISSI ${ }^{*}$, Kossi METOWOGO, Povi LAWSON-EVI, \\ Kwashie EKLU-KADÉGBÉKOU, A. Kodjo AKLIKOKOU and Messanvi GBÉASSOR
}

Centre de Formation et de Recherches sur les Plantes Médicinales (CERFOPLAM). Laboratoire de Pharmacologie et Physiologie, Faculté des Sciences, Université de Lomé. B.P:1515 Lomé-Togo.

*Corresponding author; E-mail: mabozou@gmail.com; Tel: (+228) 90358766

\begin{abstract}
The leaves of Acanthospermum hispidum (DC) are used traditionally by Togolese to treat various hepatic disorders. The aim of the present study was to evaluate the hepatoprotective effect and antioxidant activities of the hydroethanolic extract of $A$. hispidum on carbon tetrachloride $\left(\mathrm{CCl}_{4}\right)$-induced liver damage in Wistar rats. The extract was also studied for its in vitro antioxidant activity using ferric thiocyanate (FTC) and 2,2,-azobis(2-amidinopropane hydrochloride) (AAPH) methods. The hydroethanolic extract of A. hispidum administratered oraly at 250 and $500 \mathrm{mg} / \mathrm{kg}$ showed a significant hepatoprotective effect $(\mathrm{P}<0.001)$ by reducing levels of alanine amino transaminase (ALT), aspartate amino transaminase (AST) and alkaline phosphatase (ALP). The extract exhibited significant hepatoprotective and antioxidant activities. These data suggest that the hydroethanolic extracts of $\mathrm{A}$. hispidum can prevent hepatic injuries from $\mathrm{CCl}_{4}$-induced hepatotoxicity in rats and this is likely mediated through its antioxidant activities.
\end{abstract}

(c) 2015 International Formulae Group. All rights reserved.

Keywords: Hepatoprotective, Antioxidant, Acanthospermum hispidum, $\mathrm{CCl}_{4}$.

\section{INTRODUCTION}

The liver regulates many important metabolic functions. Hepatic injury is associated with distortion of these metabolic functions (Wolf, 2000). Additionally, it is the key organ of metabolism and excretion. Then it is continuously and variedly exposed to xenobiotics because of its strategic placement in the body. The toxins absorbed from the intestinal tract gain access first to the liver resulting in a variety of liver ailments. Thus liver diseases remain one of the serious heath problems (Didem et al., 2007). Modern medicines have little to offer for alleviation of hepatic diseases and it is chiefly the plant based preparations which are employed for their treatment of liver disorders. But there are not much drugs available for the treatment of liver disorders (Chaterrjee, 2000). Therefore, many folk remedies from plant origin are evaluated for its possible antioxidant and hepatoprotective effects against different chemical-induced liver damage in experimental animals. $\mathrm{CCl}_{4}$ induced hepatotoxicity model is frequently used for the investigation of hepatoprotective effects of drugs and plant extracts. The changes associated with $\mathrm{CCl}_{4}$-induced liver 
damage are similar to that of acute viral hepatitis (Suja et al., 2002). A. hispidum is herbal medicinal plant which is distributed over large areas in Togo. The ethanolic extract of the sheets and the flowers of A. hispidum presents an inhibiting activity on the development of Bacillus subtilis, Staphylococcus aureus, Streptococcus pyogenes, Salmonella typhi and Clostridium histolyticum (Fleischer et al., 2003); antiplasmodiale activity (Sanon et al., 2003) and antifongic (Hoffman et al., 2004) properties has been demonstrated. The plant is commonly used in Togolease folk medicine to treat various diseases. A. hispidum is used in the treatment of leprosy. The whole decoction of the plant is given like purgative and antidote. It is used in the treatment of the evils of belly, the wounds and the migraines. It is used in the treatment of the hepatic affections. The possible scientific hepatoprotective activity of A. hispidum leaves has not been reported. Therefore, this study aimed at evaluating the hepatoprotective and antioxidant effects of $A$. hispidum leaves by using the $\mathrm{CCl}_{4}$-induced acute liver injury model in rats.

\section{MATERIALS AND METHODS Plants materials}

Leaves of A. hispidum were collected in July 2007 in Agoè, located at $15 \mathrm{~km}$ in the North of Lomé (Togo). The samples of the plant was identified at the Laboratory of Botany and vegetable Ecology of the Faculty of Science, University of Lomé, Togo and the voucher specimen was deposited (TOGO12717) in the herbarium. The leaves were washed, dried under shade and powdered coarsely before extraction.

\section{Animals}

Male and female Wistar rats (150-200 g) were used. The animals were bred at the Laboratory of Physiology/ Pharmacology of the Faculty of Sciences, University of Lomé. They were housed under standard environmental conditions. They had a 12 hours light/dark cycle. The animals had free access to food and water. Throughout the experiments, animals were processed according to the suggested international ethical guidelines for the care of laboratory animals.

\section{Preparation of the plant extract}

The powder of A. hispidum ( $247 \mathrm{~g}$ ) was macerated in a mixture ethanol distilled water (1:1) during 72 hours under manual agitation intermittently. The filtrate was evaporated under vacuum with $45{ }^{\circ} \mathrm{C}$ by a rotary evaporator (the rotavapor Buchi R210). Yield was $23.48 \%$.

\section{Phytochemical screening}

Preliminary phytochemical composition of the hydroethanolic extract was studied using the following tests (Itoria et al., 2011): alkaloids with Mayer's and Dragandroff's test, flavonoids with Shinoda and Zinc hydrochloride reduction test, tannin with Ferric chloride and Vanillin hydrochloride test and saponins with the ability to produce suds.

\section{Determination of total phenols}

Gallic acid was used to make the calibration curve $[0.05 ; 0.15 ; 0.2 ; 0.25$ $\mathrm{mg} / \mathrm{mL}$ ]. $500 \mu \mathrm{l}$ of extract or gallic acid were mixed with $0.2 \mathrm{~mL}$ Folin-Ciocalteu reagent 2 $\mathrm{mL}$ of $\mathrm{H}_{2} \mathrm{O}$, and $1 \mathrm{~mL}$ of $15 \% \mathrm{Na}_{2} \mathrm{CO}_{3}$ and the mixture was measured at $765 \mathrm{~nm}$ after $15 \mathrm{~min}$ at room temperature. The mean of three readings was used and the total phenolic content was expressed in milligram of gallic acid equivalents/g extract (Didem et al., 2007).

\section{Determination of total flavonoids}

Flavonoids were expressed as quercetin equivalent. Quercetin was used to make the calibration curve $[1 ; 5 ; 12.5 ; 25 ; 50 ; 75 ; 100$ $\mu \mathrm{g} / \mathrm{mL}]$. The standard solutions or extracts $(500 \mu \mathrm{l})$ were mixed with $1.5 \mathrm{~mL}$ methanol, $0.1 \mathrm{~mL} 10 \%$ aluminum chloride (w/v), $0.1 \mathrm{~mL}$ of $1 \mathrm{~mol} / \mathrm{L}$ sodium acetate and $2.8 \mathrm{~mL}$ distiller water. The volume of $10 \%$ aluminum chloride was substituted by the same volume of 
distilled water in blank. After incubation at room temperature for $30 \mathrm{~min}$, the absorbance of the reaction mixture was measured at 415 $\mathrm{nm}$. The mean of three readings was used and the total flavonoid content was expressed in milligram of quercetin equivalents/g extract (Didem et al., 2007).

\section{$\mathrm{CCl}_{4}$-induced hepatotoxicity}

We induced the hepatotoxicity with $\mathrm{CCl}_{4}$ according to the method of Suja et al. (2004). The animals were divided into 7 groups of 7 animals each. Group I served as normal control and received distilled water (0.5 mL/100g of body weight (bw), per os) daily for 3 days and received corn oil (2.5 $\mathrm{mL} / \mathrm{kg}$ per os) on day 3; $60 \mathrm{~min}$ after the administration of distilled water. Group II served as $\mathrm{CCl}_{4}$ control and received distilled water $(0.5 \mathrm{~mL} / 100 \mathrm{~g}$, per os) daily for 3 days and received $\mathrm{CCl}_{4}$ : corn oil $(1: 1),(2.5 \mathrm{~mL} / \mathrm{kg}$ bw.per os) on day 3; $60 \mathrm{~min}$ after the administration of distilled water. Groups IIIIV were treated with of A. hispidum at doses of 250 , and $500 \mathrm{mg} / \mathrm{kg}$ per os, respectively, for 3 days and received $\mathrm{CCl}_{4}$ : corn oil $(1: 1)$, (2.5 ml/kg bw., per os) on days 3; $60 \mathrm{~min}$ after administration of extract. Group VI was treated with the reference drug silymarin at dose of $100 \mathrm{mg} / \mathrm{kg}$ per os for 3 days and received $\mathrm{CCl}_{4}$ : corn oil (1:1), $(2.5 \mathrm{ml} / \mathrm{kg}$ bw., per os) on day $3 ; 60 \mathrm{~min}$ after administration of silymarin.

Forty eight (48) hours after the administration of $\mathrm{CCl}_{4}$ the animals were anaesthetized with ether, then blood was taken on the level of the retro-orbital sine. This blood was centrifuged and in the serum the biochemical parameters such as: Alanine aminotransferase (ALT), the aspartate aminotransferase (AST), phosphatase alcaline (PAL) were proportioned.

Assessment of antioxidant activities of extracts

$\mathrm{FeCl}_{2}$-ascorbic acid stimulated lipid peroxidation in liver homogenate

The antilipid peroxidant effect of $A$. hispidum was studied in vitro, following the modified method of Jin et al. (2005). Briefly,
$2 \mathrm{~g}$ of rat liver tissue was sliced and homogenised with $150 \mathrm{mM} \mathrm{KCl-Tris-HCl}$ buffer $(\mathrm{pH}$ 7.2). The reaction mixture was composed of $0.35 \mathrm{~mL}$ liver homogenate, 0.1 $\mathrm{mL}$ Tris- $\mathrm{HCl}$ buffer $(\mathrm{pH} 7.2) ; 0.05 \mathrm{~mL}$ of $\mathrm{FeCl}_{2} 4 \mathrm{mM} ; 0.05 \mathrm{~mL}$ of ascorbic acid 0.1 $\mathrm{mM}$ (AA) and $0.05 \mathrm{ml}$ of various concentrations of $\mathrm{A}$. hispidum extract. The mixture was incubated at $37^{\circ} \mathrm{C}$ for 1 hour in capped tubes. Then $0.5 \mathrm{~mL}$ of $\mathrm{HCl}(1 \mathrm{~N}), 0.2$ $\mathrm{mL}$ of sodium dodecyl sulphate (SDS: $9.8 \%$ ), $0.9 \mathrm{~mL}$ distilled water and $2 \mathrm{~mL}$ of thiobarbituric acid (TBA: $0.6 \%$ ) were added to each tube and vigorously shaken. The tubes were placed in a boiling water bath at $100{ }^{\circ} \mathrm{C}$ for $30 \mathrm{~min}$. After cooling, $5 \mathrm{ml}$ of butanol was added and centrifuged at $3000 \mathrm{rpm}$ for $25 \mathrm{~min}$. The absorbance of the supernatant was measured at $532 \mathrm{~nm}$.

\section{Anti-Hemolysis activity of A. hispidum induced by 2,2,-azobis(2-amidinopropane hydrochloride)(AAPH)}

The Anti-Hemolysis Activity of $A$. hispidum was studied in vitro, following the method of Qin et al. (2002), Yifan et al. (2009) and Nitya et al. (2012). Rats were anaesthetised with ether. Blood (5-7 ml/rat) obtained from the sine retro-orbital was collected into heparinized tubes. Erythrocytes were separated from plasma and the buffy coat, and were washed three times with 5 vol of phosphate-buffered saline (PBS), $\mathrm{pH}$ 7.4. During the last wash, the erythrocytes were centrifuged at $3000 \mathrm{~g}$ for $10 \mathrm{~min}$ to obtain a packed cell preparation. The packed erythrocytes were then suspended in 4 vol of PBS solution. The peroxidation of erythrocyte membranes was studied using a Azo compounds (AAPH) generate free radicals by their unimolecular thermal decomposition in the aqueous region. Two milliliters of the erythrocyte suspension were mixed with $2 \mathrm{ml}$ of PBS solution containing varying amounts of $A$. hispidum $(2.5-40 \mathrm{M})$. Two milliliters of $200 \mathrm{mM}$ AAPH in PBS were then added to the mixture. The reaction mixture was shaken gently while being incubated at $37{ }^{\circ} \mathrm{C}$ for 3 hours. After incubation, the reaction mixture was diluted with 8 vol of PBS and was centrifuged at $3000 \mathrm{~g}$ for $5 \mathrm{~min}$. The absorbance (A) of the supernatant fraction at $540 \mathrm{~nm}$ was 
recorded in a spectrophotometer (Beckman Instruments, Fullerton). The percentage of inhibition was calculated by the following equation:

$\%$ Inhibition $=\left[\mathrm{A}_{\mathrm{AAPH}}-\mathrm{A}_{\text {extract }} / \mathrm{A}_{\mathrm{AAPH}}\right]$

Where $\mathrm{A}_{\text {extract }}$ is the absorbance of the sample containing either the extract or ascorbic acid, and $\mathrm{A}_{\mathrm{AAPH}}$ is the absorbance of the sample containing neither extract nor ascorbic acid was used as a positive control.

Five replicates were performed for each extract.

\section{Statistical analysis}

The results were analyzed using the software Systat 11.0. They are expressed as mean \pm SEM. One way analysis of variance (ANOVA) followed by Fischer's "Least Significant Difference" was used to compare the various groups. A $p<0.05$ was considered to be statistically significant.

\section{RESULTS}

Effects of $A$. hispidum extract on serum AST, ALT and PAL levels in $\mathrm{CCl}_{4}$-intoxicated rats

Administration of $\mathrm{CCl}_{4}$ to rats caused significant $(\mathrm{p}<0.05)$ increase in serum enzymes like AST, ALT, and PAL, compared to normal control rats. Treatment with $A$. hispidum $(\mathrm{AH})$ caused significant $(\mathrm{p}<0.05)$ reduction of these values, almost comparable to the Silymarin (S) treated group (Figures.1$3)$.

Effects of $A$. hispidum on oxidative stress Effects of $A$. hispidum on $\mathrm{FeCl}_{2}$-ascorbic acid stimulated lipid peroxidation

A. hispidum showed very potent inhibition of $\mathrm{FeCl}_{2}-\mathrm{AA}$ stimulated rat liver lipid peroxidation in vitro. There was a significant $(\mathrm{p}<0.05)$ increase of malondialdehyde (MDA) in $\mathrm{FeCl}_{2}-\mathrm{AA}$ treated rat liver homogenate, compared to normal control without $\mathrm{FeCl}_{2}-\mathrm{AA}$ (Table 1).

Effects of A. hispidum on AAPH-induced hemolysis of erythrocytes

The influence of $A$. hispidum extract on in vitro erythrocyte hemolysis was examined by incubating rat erythrocytes in the presence of $200 \mathrm{mM}$ AAPH as an initiator of oxidation. The A. hispidum extract provided a strong inhibitory effect against erythrocyte hemolysis. The extract inhibited in vitro AAPH-induced erythrocytes hemolysis in a dose-dependent manner (Table 2).

\section{Phytochemical screening}

Qualitative phytochemical tests revealed the presence of alkaloids, flavanoids, tannins and saponins (Table 3). Quantitative phytochemical studies showed that the extracts contained phenols and flavonoids (Table 4).

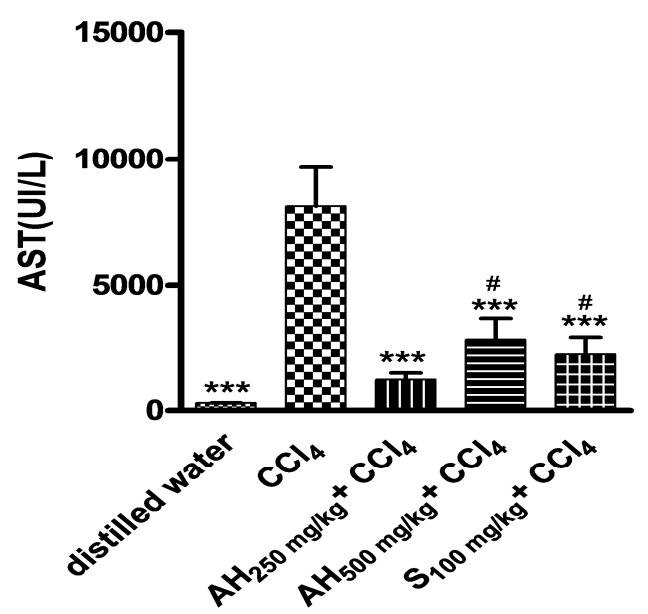

Figure 1: Effects of $A$. hispidum extract on serum AST levels in $\mathrm{CCl}_{4}$-intoxicated rats. The data are expressed as mean \pm S.E.M $(n=7)$. ${ }^{*} P<0.05,{ }^{* *} P<0.01$, *** $p<0.001$ as compared with the $\mathrm{CCl}_{4 \text { control }}$ \# $\mathrm{P}<0,05$ as compared with distilled water. The various groups were compared by ANOVA followed by Fischer' LSD. 


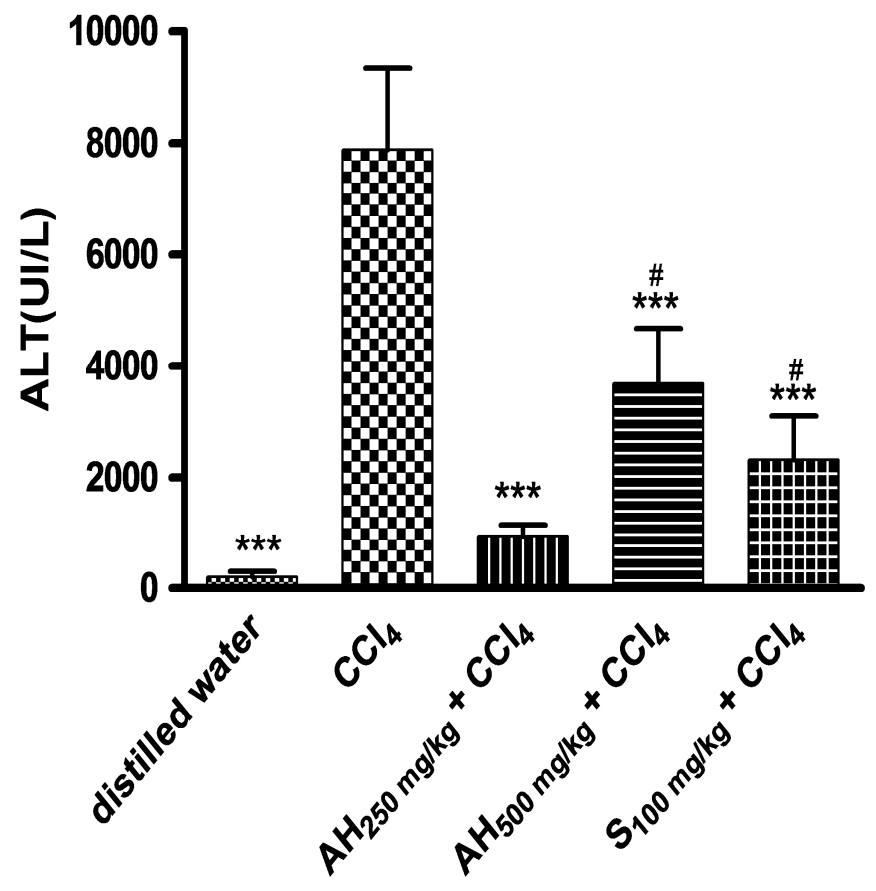

Figure 2: Effects of $A$. hispidum extracts on serum ALT levels in $\mathrm{CCl}_{4}$-intoxicated rats. The data are expressed as mean \pm S.E.M $(n=7)$. ${ }^{*} P<0.05$, ** $P<0.01$, *** $p<0.001$ as compared with the $\mathrm{CCl}_{4}$ control, $\# \mathrm{P}<0,05$ as compared with distilled water. The various groups were compared by ANOVA followed by Fischer' LSD.

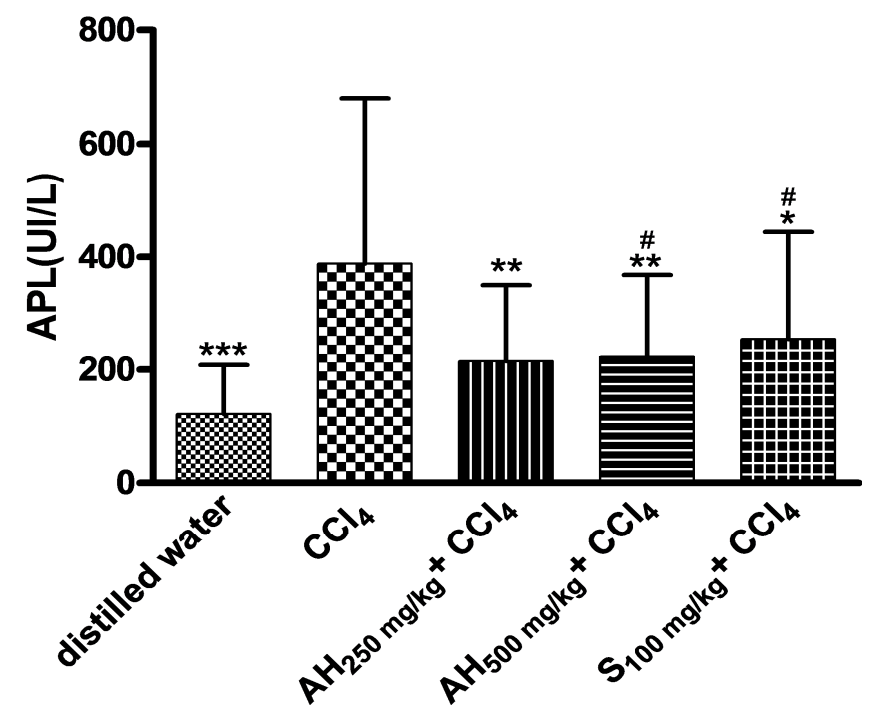

Figure 3: Effects of $A$. hispidum extract on serum PAL levels in $\mathrm{CCl}_{4}$-intoxicated rats. The data are expressed as mean \pm S.E.M $(n=7)$. ${ }^{*} P<0.05, * * P<0.01$, *** $p<0.001$ as compared with the $\mathrm{CCl}_{4}$ control, \# $\mathrm{P}<0,05$ as compared with distilled water. The various groups were compared by ANOVA followed by Fischer' LSD. 
Table 1: Inhibitory effect of A. hispidum extract on $\mathrm{FeCl}_{2}$-ascorbic acid-induced lipid peroxidation in rat liver homogenate in vitro.

\begin{tabular}{lcc}
\hline Treatment & Dose & MDA \\
\cline { 2 - 3 } & $\mathbf{( m g / m l )}$ & $\mathbf{( n M / g ~ o f ~ l i v e r ) ~}$ \\
\hline Normal control & & $12.47 \pm 2.10$ \\
$\mathrm{FeCl}_{2}$-AA & & $78.73 \pm 4.95$ \\
\hline & 0.05 & $50.53 \pm 0.70^{*}$ \\
$\mathrm{FeCl}_{2}$-AA + Quercetin & 0.10 & $38.31 \pm 1.10^{* *}$ \\
& 0.15 & $36.90 \pm 6.10^{* *}$ \\
& 0.20 & $30.79 \pm 5.90^{* *}$ \\
& 0.25 & $22.33 \pm 5.50^{* *}$ \\
$\mathrm{FeCl}_{2}$-AA + A. hispidum & 0.05 & $59.93 \pm 4.48^{*}$ \\
& 0.10 & $51.94 \pm 2.00^{*}$ \\
& 0.15 & $32.20 \pm 1.50^{* *}$ \\
& 0.20 & $12.53 \pm 3.70^{* * *}$ \\
& 0.25 & $35.49 \pm 4.11 * *$ \\
& 0.25 & $14.35 \pm 4.48^{* * *}$ \\
\hline
\end{tabular}

The data are expressed as mean \pm S.E.M $(n=3) .{ }^{*} P<0.05,{ }^{* *} P<0.01$, *** $p<0.001$ compared to $\mathrm{FeCl}_{2-}$ AA group.

Table 2: Effects of A. hispidum on AAPH-induced hemolysis of erythrocytes. Data are expressed as mean $\pm \mathrm{SEM}$.

\begin{tabular}{lccc}
\hline Treatment & Dose & \% of inhibition & IC $_{\mathbf{5 0}}$ \\
\cline { 2 - 4 } & $\mathbf{( \mathbf { m g } / \mathbf { m l } )}$ & & $\mathbf{( m g / m l})$ \\
\hline \multirow{3}{*}{ Ascorbic Acid + AAPH } & 0.10 & $84 \pm 0.004$ & \\
& 0.25 & $96 \pm 0.003$ & 0.06 \\
& 0.50 & $97 \pm 0.001$ & \\
\hline \multirow{2}{*}{ A. hispidum + AAPH } & 1.00 & $98 \pm 0.002$ & 0.43 \\
& 0.10 & $05 \pm 0.044$ & \\
\hline
\end{tabular}

Table 3: Phytochemicals tests in hydroethanolic extract of A. hispidum.

\begin{tabular}{lc}
\hline Experiment & A. hispidum extract \\
\hline Alkaloids & ++ \\
Flavonoids & ++ \\
Tannin & +++ \\
Saponins & +++ \\
\hline+++ : very abundant ; ++ : Abundant. &
\end{tabular}

Table 4: Total phenolic and total flavonoid contents of A. hispidum.

\begin{tabular}{lcc}
\hline Extracts & Total phenolic content & Total flavonoid content \\
\hline & $(\mathbf{m g}$ GAE/ g extract $)$ & $(\mathbf{m g} \mathbf{Q E} / \mathbf{g}$ extract $)$ \\
A. hispidum & $155 \pm 0.6$ & $25.43 \pm 0.4$ \\
\hline GAE = gallic acid equivalent; $\mathrm{QE}=$ quercetin equivalent.
\end{tabular}




\section{DISCUSSION}

$\mathrm{CCl}_{4}$-induced hepatotoxicity model is frequently used for the investigation of hepatoprotective effects of drugs and plant extracts. The changes associated with $\mathrm{CCl}_{4^{-}}$ induced liver damage are similar to that of acute viral hepatitis (Suja et al., 2002). $\mathrm{CCl}_{4}$ is biotransformed by cytochrome P-450 in the liver endoplasmic reticulum to the highly reactive trichloromethyl free radical $\left(\mathrm{CCl}_{3}{ }^{\circ}\right)$. This free radical in turn reacts with oxygen to form a trichloromethyl peroxy radical $\left(\mathrm{CCl}_{3} \mathrm{OO}^{\circ}\right)$. Both radicals are capable to binding proteins or lipids, or abstracting a hydrogen atom from an unsaturated lipid, thus, initiating lipid peroxidation, generate oxidative stress (Didem et al., 2007). This state involves the depletion of natural antioxidants such as the superoxyde dismutase (SOD), catalase (CAT), glutathione (GSH) (Suja et al., 2004). It results from the hepatolysis which increasing the rate of the serum enzymes such as ALT, AST and ALP (Shanmugasundaram et al., 2006). Transaminases and alkaline phosphatase are plasmatic enzymes of hepatic origin which make it possible to explore the state of liver (Suja et al., 2004). A significant rise in the serum concentration of these enzymes is a sign of hepatic intoxication. In this study, ALT, AST and ALP activities levels significantly increased in rats treated with $\mathrm{CCl}_{4}$ and decreased in rats treated with $\mathrm{CCl}_{4}$ and A. hispidum $(250 \mathrm{mg} / \mathrm{kg}$ and $500 \mathrm{mg} / \mathrm{kg}$ ). A. hispidum thus have hepatoprotectives effects. Clinical studies reported that reactive oxygen species are associated with many diseases, including hepatitis, liver injury (Lee et al., 2004). In order to clarify the mode of action of A. hispidum in vitro, lipid peroxidation experiments were carried out. Lipid peroxidation is accepted to be one of the main causes of carbon tetrachloride-induced liver injury, and is mediated by the production of free radical derivatives of carbon tetrachloride. Thus, antioxidant activity and/or the inhibition of free radicals generation is important in terms of protecting the liver from carbon tetrachloride-induced damage (Hye et al., 2002). In vitro lipid peroxidation in a liver homogenate can proceed in a nonenzymatic way. The process is induced by ascorbate in the presence of $\mathrm{Fe}^{2+} / \mathrm{Fe}^{3+}$, and it has been reported that $\mathrm{Fe}^{2+}$ and ascorbic acid stimulated lipid peroxidation in rat liver microsomes and mitochondria (Yong et al.,2008). According to the results obtained, A. hispidum inhibited $\mathrm{FeCl}_{2}$-ascorbic acid stimulated lipid peroxidation in liver homogenate (Table 2). A. hispidum was found to be effective in decreasing malondialdehyde (MDA) production in liver of rats treated with $\mathrm{FeCl}_{2}$-ascorbic acid showing its antilipid peroxidation effects. AAPH is a water soluble radical generator that produces a range of free radicals at a constant rate without the use of enzymes or biotransformation (Nitya et al., 2012). Therefore, oxidative hemolysis of erythrocytes induced by AAPH and its protection by compounds act as a good model system to screen the test compounds for their antioxidant behavior (Arnab et al., 2008). According to the results obtained, A. hispidum extract also inhibited AAPH induced oxidative hemolysis of erythrocytes (Table 2). Phenolic antioxidants are reported to be able to quench oxygen-derived free radicals as well as substrate-derived free radicals, protect cell constituents against oxidative damage and, therefore, limit the risk of various diseases associated to oxidative stress (Scalbert et al., 2005). The results of the qualitative characterization indicate an abundance of flavonoids in each extract. These results are confirmed by the quantitatives tests (Table 3 ). Fleischer et al. (2003) showed that $A$. hispidum contains polyphenols. There is a correlation between the quantity of flavonoids and the antioxidant capacity $\left(\mathrm{r}^{2}=0.9846\right.$ and $\mathrm{p}<0.001)$. Flavonoids have an antihepatotoxic activity (Lahouel et al., 2004; Amani et al., 2006). This suggests that in fact, the flavonoids confer on extract the antioxidant capacity which is at the base of the hepatoprotectives effects (Didem et al., 2007). Plant antioxidants have been shown to protect erythrocytes against hemolysis induced by AAPH. Qin et al. (2002) reported 
that treating rat erythrocytes with a cocoa extract containing flavonoid inhibits hemolysis induced by AAPH in vitro. Arnab et al. (2008) reported that treating erythrocytes with curcumin (flavonoid) inhibits AAPHinduced hemolysis, as evidenced by reduced release of hemoglobin. Similarly, Yifan et al. (2009) reported that treating erythrocytes with quercetin (flavonoid) inhibits AAPH-induced hemolysis. The investigators attributed the antihemolytic actions of these plant-derived compounds to their antioxidant property (Yifan et al., 2009). Increasing evidence suggests that flavonoids protect cell not only by buffering free radicals but also by altering cell membrane properties (Arora et al., 2000). Like in vitro lipid peroxidation inhibition induced by AAPH free radicals $\left(\mathrm{R}^{\circ}\right.$ and $\mathrm{ROO}^{\circ}$ ), A. hispidum compound inhibited in vivo lipid peroxidation induced by $\mathrm{CCl}_{4}$ free radicals, $\mathrm{CCl}_{3}{ }^{\circ}$ and $\mathrm{CCl}_{3} \mathrm{OO}$. The correlation between the quantity of flavonoids and the antioxidant capacity suggests that flavonoids attributed to the extract its antioxidant properties which were at the base of its hepatoprotectives effects.

\section{Conclusion}

A. hispidum leaves has hepatoprotectives effects that explains its use in traditional medecine. The active compounds of A. hispidum leaves, which are responsible for antioxidant and hepatoprotectives effects, have not been isolated in this study. Therefore, further studies should be conducted to isolate the active compounds that are responsible for the hepatoprotectives effects.

\section{REFERENCES}

Arora A, Byrem TM, Nair MG, Strasburg GM. 2000. Modulation of liposomal membrane fluidity by flavonoids and isoflavonoids. Arch. Biochem. Biophys., 373: 102-109.

Amani Awaad S, Maitland BDJ, Soliman G. A. 2006. Hepatoprotective activity of Schouwia thebica webb. Bioorganic \&
Medicinal Chemistry Letters, 16: 46244628.

Arnab Banerjee A, Kunwar B, Mishra KI, Priyadarsini. 2008. Concentration dependent antioxidant/pro-oxidant activity of curcumin Studies from AAPH induced hemolysis of RBCs. ChemicoBiological Interactions, 174: 134-139.

Chaterrjee TK. 2000. Medicinal Plants with Hepatoprotective Properties. Books and Applied Allied (P) Ltd.: Calcutta; 143.

Didem Deliorman O, Nil“Ufer O, Ender E, Fatma E. 2007. Hepatoprotective effect of Vitis vinifera leaves on carbon tetrachloride-induced acute liver damage in rats. Journal of Ethnopharmacology, 112: $145-151$.

Fleischer TC, Ameade EPK, Sawer IK. 2003. Antimicrobial activity of the leaves and flowering tops of Acanthospermum hispidum. Fitoterapia, 74: 130-132.

Hoffman BR, Delasalas H, Blanco K, Wiederhold N, Lewis RE., Williams L., 2004. Screening of antibacterial and antifungal activities of ten medicinal plants from Ghana. Pharmaceutical Biology, 42: 13-17.

Hye Gwang Jeong, Ho Jin You, Sung Jun Park, Ae Ran Moon, Young Chul Chung, Shin Keon Kang, Hyo Kon Chun, 2002. Hepatoprotective effects of $18 \beta$ glycyrrhetinic acid on carbon tetrachloride-induced liver injury: inhibition of cytochrome p450 2e1 expression. Pharmacological Research, 46: 221-227.

Itoria Priyank, Jain Shonu, Jain Gaurav, Dubey BK. 2011. Pharmacognostic evaluation and phytochemical screening of leucas cephalotes. International Journal of Phytopharmacy, 1: 15-26.

Lee J, Koo N, Min DB. 2004. Reactive Oxygen Species, Aging, and Antioxidative Nutraceuticals. Comprehensive Reviews in Food Science and Food Safety, 3: 21-33.

Jin Ying-Shan, Jae-Hoon S, Tae-Heum S, Hae-Ik Rhee, Myeong-Hyeon Wang 2005. Hepatoprotective and antioxidant 
effects of Morus Bombyciskoidzumi on $\mathrm{CCl}_{4}$-induced liver damag. Biochemical and Biophysical Research Communications, 329: 991-995.

Lahouel M, Boulkour S, Segueni N, Fillastre JP. 2004. Effet protecteur des flavonoïdes contre la toxicité de la vinblastine, du cyclophosphamide et du paracétamol par inhibition de la peroxydation lipidique et augmentation du glutathion hépatique. Pathologie Biologie, 52: 314-322.

Nitya Jani, James Ziogas, James AA, CE. Wright. 2012. Exogenous glutathione is essential in the testing of antioxidant capacity using radical-induced hemolysis. Journal of Pharmacological and Toxicological Methods, 65: 142-146.

Qin Yan Zhu, Roberta Holt R., Sheryl A. Lazarus, Timothy J. Orozco, And Carl L. Keen, 2002. Inhibitory effects of cocoa flavanols and procyanidin oligomers on free radical-induced erythrocyte hemolysis. Exp. Biol. Med., 227: 321329.

Sanon S, Ollivier E, Azas N, Mahiou V, Gasquet M, Ouattara CT. Nebie IT, raore AS, Esposito F, Balansard G, TimonDavid P, Fumoux F. 2003. Ethnobotanical survey and in vitro antiplasmodial activity of plants used in traditional medicine in Burkina Faso. Journal of Ethnopharmacology, 86: 143147.

Scalbert A, Manach C, Morand C, Rémésy C, Jiménez L. 2005. Dietary polyphenols and the prevention of disease. Crit. Rev. Food Sci. Nutr., 45: 287-306.
Shanmugasundaram $\mathrm{P}$, Venkataraman $\mathrm{S}$. 2006. Hepatoprotective and antioxidant effects of Hygrophila auriculata (k.schum) heine acanthaceae root extract. Journal of Ethnopharmacology, 104: 124-128.

Suja SR, Latha PG, Pushpangadan P, Rajasekharan S. 2002. Aphrodisiac property of Helminthostachys zeylanica in mice. Journal of Tropical Medicinal Plants, 3: 191-195.

Suja SR, Latha PG, Pushpangadan P, Rajasekharan S. 2004. Evaluation of hepatoprotective effects of Helminthostachys zeylanica hook against carbon tetrachloride-induced liver damage in wistar rats. Journal of Ethnopharmacology, 92: 61-66.

Wolf PL. 2000. Biochemical diagnosis of liver diseases. Indian Journal of Clinical Biochemistry, 14: 59-90.

Yifan Chen, Patricia Deuster, 2009. Comparison of quercetin and dihydroquercetin: Antioxidantindependent actions on erythrocyte and platelet membrane. Chemico-Biological Interactions, 182: 7-12.

Yong Pil Hwang, Jae Ho Choi, Eun Hee Han, Hyung Kyun Kim, Shin Keon Kang, Young Chul Chung, Hye Gwang Jeong, 2008. Protective mechanisms of Aralia continentalis extract against tert-butyl hydroperoxide-induced hepatotoxicity: In vivo and in vitro studies. Food and Chemical Toxicology, 46: 3512-3521. 